topography, history, natural history, rural economy and general culture of the Lake District. Lectures and demonstrations are also planned.

The board bought Brockhole in 1966 with the help of a grant, but there was a long delay before doing anything with it because of the financial squeeze. At long last, authority to go ahead with the development and management of the centre was given by the Government in November 1967. Now the board is trying to find a director for the centre. The salary offered, initially in the range $£ 1,725-£ 2,105$, may be considered low by national standards, but the board hopes that the situation of Brockhole and other amenities will more than compensate for this. The authority to go ahead with the scheme was given under section 86 of the National Parks Act, 1949. This act, however, has been superseded by the new Countryside Act, 1968,

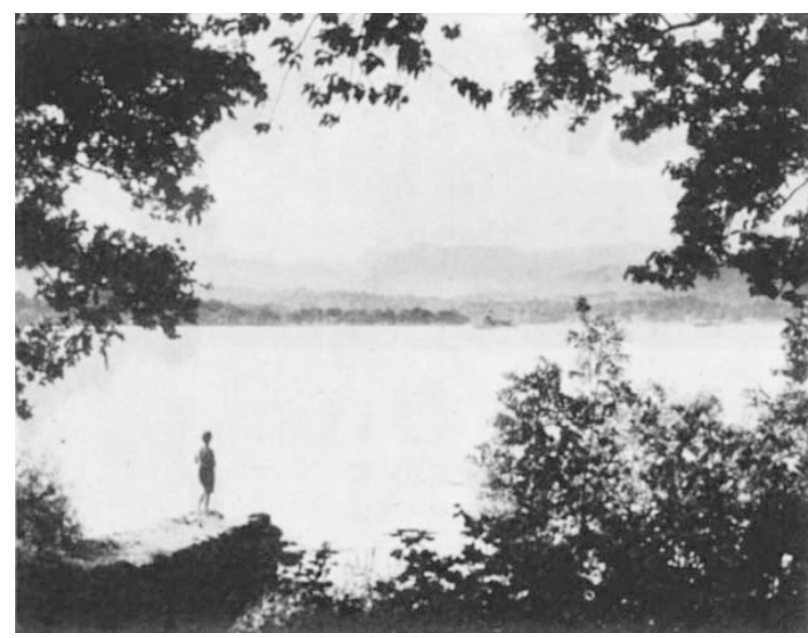

National Park Centre at Brockhole, Windermere. (Photo: G. V. Berry.)

which came into force on August 3. In effect the act confers "new powers on local authorities and other bodies for the conservation and enhancement of natural beauty and for the benefit of those resorting to the countryside ...". The National Parks Commission has been disbanded in favour of a Countryside Commission which has additional powers and duties, although in practice it has very little more executive powers than its predecessor. One of the most important proposals is that local authorities now have considerable powers to set up country parks for recreation. These should relieve the pressure on the National Parks, which are increasingly suffering from the demands of the motor car.

On the question of access, the new act extends the type of land on which access agreements may be negotiated from the mountain, heath and foreshore of the 1949 act to include rivers, canals and woodlands. Statutory water undertakings and the Forestry Commission have increased powers to provide for recreation on reservoirs and in forests. Of particular interest to the Lake District is the provision which allows local planning authorities to make by-laws for the control of boating on National Park lakes. Inclusion of such a clause was made at the committee stage in the House of Lords and it should be effective in dealing with nuisance and damage from boats.
Noise, a problem suffered particularly seriously at Windermere, should also come within the scope of this clause.

\section{Millom to Close}

The Millom Hematite Ore and Iron Company, where the first commercial spray steelmaking plant was put into operation, is to close. The announcement last week said that the costs of making pig iron at Millom were now above the current prices, in part because of cheap imports from Russia and East Germany. Competition with the British Steel Corporation is also a problem for small independent producers, and Millom has been making losses for some months.

The decision is a particularly sad one, because Millom was the only British firm willing to try out the spray steelmaking techniques developed by the British Iron and Steel Research Association. A pilot plant was built at Millom which has now been in production for some eighteen months, and which has proved the feasibility of the technique outside the laboratory. Without Millom, the technique might still be a laboratory curiosity, as BISRA scientists frankly admit. As it is, the success of the plant at Millom has encouraged Lancashire Steel to build a plant at its works at Irlam, and Shelton Iron and Steel Co. is also building a spray steel plant. BISRA has set up a wholly owned subsidiary company, Spray Steelmaking Limited, to market the process in partnership with Humphreys and Glasgow, the chemical engineering company.

Millom's attempts to become steelmakers were never very popular in official circles. The Iron and Steel Board refused in January 1967 to give Millom sanction to raise $£ 1$ million for an expansion plan based on the spray technique, arguing that there were no grounds for increasing the total productive capacity of British steelworks when many of the works were operating well below full capacity. In any case, the official view has always been that production should be concentrated in as few large centres as possible, in order to make the most of economies of scale. The spray technique, which costs very much less to install than does traditional steelmaking equipment, reduces the force of this argument. Finally, the Iron and Steel Board gave grudging approval for the plan to go ahead, but it seems that spray steelmaking came too late to save Millom.

The decision to close will come as a severe shock to the town of Millom, which relies almost exclusively on the ironworks. Just over 1,000 people will be made redundant by the closure, in an area which already has more than its share of unemployment. In the past, Millom has not always been included in the north-west development area, which has made it harder to attract new industry, and it seems certain that many of those made redundant will have to move away from the area to find work.

Although this is a poor reward for showing the way with the new process, spray steelmaking itself seems to be making good progress. The process, in which pig iron is atomized by a blast of oxygen and is converted to steel as it falls into a receiving ladle, does not feature in the immediate development plans of the British Steel Corporation, but the workers at the BISRA laboratories are confident of its long-term importance. 